\title{
Aa. Vv., Tristan et la Musique de son temps
}

\section{Daniela Dalla Valle}

\section{(Q) OpenEdition}

\section{Journals}

\section{Edizione digitale}

URL: http://journals.openedition.org/studifrancesi/3716

DOI: $10.4000 /$ studifrancesi.3716

ISSN: 2421-5856

\section{Editore}

Rosenberg \& Sellier

\section{Edizione cartacea}

Data di pubblicazione: 1 décembre 2012

Paginazione: 561

ISSN: 0039-2944

\section{Notizia bibliografica digitale}

Daniela Dalla Valle, «Aa. Vv., Tristan et la Musique de son temps», Studi Francesi [Online], 168 (LVI | III) | 2012, online dal 30 novembre 2015, consultato il 07 mars 2021. URL: http://journals.openedition.org/ studifrancesi/3716 ; DOI: https://doi.org/10.4000/studifrancesi.3716

Questo documento è stato generato automaticamente il 7 mars 2021.

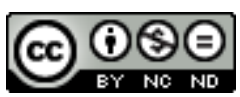

Studi Francesi è distribuita con Licenza Creative Commons Attribuzione - Non commerciale - Non opere derivate 4.0 Internazionale. 


\title{
Aa. Vv., Tristan et la Musique de son temps
}

\author{
Daniela Dalla Valle
}

\section{NOTIZIA}

Tristan et la Musique de son temps. Actes de la journée d'études du vendredi 4 février 2011, «Cahiers Tristan l'Hermite», XXXIII, 2011, pp. 125.

1 Questo numero dei Cahiers Tristan raccoglie una serie di articoli (comunicazioni nella Giornata Tristan 2011) consacrati a un particolare aspetto della poesia tristaniana: il contatto fra Tristan e la musica. È un aspetto estremamente importante, anche se in questa sede è stato affrontato in termini non esaustivi, tanto da suggerire un ulteriore incontro di studi sull'argomento.

Dopo la presentazione di Alain GÉNETIOT, il primo articolo è quello di Emmanuel BURY, fondamentale e molto ricco di rinvii puntuali al discorso d'insieme in cui la Giornata s'inserisce (Genres littéraires et modes musicaux à l'époque de Tristan, pp. 9-21); altrettanto interessante è la puntualizzazione di Françoise GRAZIANI su L'Orphée di Tristan («Cherche des beaux accords la plus parfaite idée»: la voix d'Orphée et son «effet», pp. 22-33), che raccorda nella sua analisi il testo tristaniano con gli Orfei italiani (Monteverdi, Peri...). Georgie DUROSoIR si sofferma invece sul percorso fatto dalla poesia Monarque le plus glorieux, scritta da Tristan per il Ballet des Quatre Monarchies Chrétiennes (1635), quando diventa oggetto di due parodie pubblicate nel 1640 in La Philomèle séraphique (De Gaston à Philomèle: Histoire d'une Poésie de Tristan, pp. 35-48); mentre Thomas LECONTE si allontana da Tristan, per occuparsi delle "citations pour boire" pubblicate da Ballard (De l'influence des libertins sur le divertissement mondain du premier XVII siècle: le répertoire de "Chansons pour boire" publié par Ballard, pp. 49-96); il testo prevede, in Annexe, alcune strofe bacchiche pubblicate da Ballard tra il 1625 e il 1660. Infine Pierre Gatulle si sofferma sul rapporto fra Tristan e Estienne Moulinié, autore e compositore (Les identités d'auteur et de compositeur de Tristan et de Moulinié par la publication: la dignité et 
l'honorabilité, pp. 97-107). Il volumetto si chiude con la descrizione di un concerto ( $L a$ Lyre de Tristan, pp. 108-111), dato a Versailles il 4 gennaio 2010, presentato da sophie LANDY-CLUZET. 